\title{
16 Experimentaciones. Con el libro, con la palabra
}

Este apartado está dedicado a la experimentación con soportes y formas textuales como algo privativo de las editoriales independientes, según fueron conceptualizadas arriba. Antes de ingresar en el tema, vuelvo a remarcar que el hecho de que un proyecto editorial sea susceptible de ser caracterizado como independiente no supone de manera automática que lo que edite sean libros y literatura de "calidad", así como, inversamente, tampoco habría que deducir que una gran firma, por el hecho de poseer capacidad financiera y someter a una racionalidad economicista el proceso productivo, está exenta de la posibilidad de elaborar "buenas" publicaciones o construir un "buen" catálogo. Lo que estaría comprometido acá es algo bien diferente: la experimentación como algo que se resuelve, fundamentalmente, en el plano de las literaturas locales. De tal suerte que, con sus riesgos intrínsecos, entre ellos, con la posibilidad de que efectivamente dé lugar a soportes y formas innovadoras o no, la experimentación sí constituiría una variable diferencial. La ecuación es muy simple: la producción industrial a más o menos gran escala, a diferencia de la artesanal, tiene un margen muy reducido para la exploración de técnicas, materiales y formatos. Mientras que, en lo que respecta estrictamente a los textos, habría que considerar que las configuraciones demasiado alejadas de los patrones de consumo estándares representan un riesgo económico excesivamente alto $\mathrm{y}$, por lo tanto, inviables para cualquier racionalidad economicista. La edición independiente, local, de baja proyección de ventas, sería, en este sentido, el laboratorio que la industria cultural jamás podría ser. Quiero remarcar, además, que el criterio "calidad” no es, en mis planteos, una variable de consideración. No solo porque la evaluación bajo tal premisa siempre encierra una cuota de subjetividad, sino también porque, si se supone que una novela prolijamente estructurada, con un argumento verosímil y personajes sólidos es una "buena" novela, es decir, lo que suelen publicar las editoriales establecidas en conformidad con fórmulas transmisibles en cualquier programa de escritura creativa, lo que estarían haciendo las editoriales que acá interesan es producir literatura anómala, no alineada, valga decir, en casos, "mala" literatura. De algún modo -se podría sostener-, estarían generando condiciones de posibilidad para el célebre "Llamado por los malos poetas” (2004), de Fogwill. Porque, en realidad, no se necesitaría más literatura "profesional", sino que, de acuerdo con su planteo,

Ә Open Access. (C) 2019 Jorge J. Locane, published by De Gruyter. (c) BY-NC-ND This work is licensed under the Creative Commons Attribution-NonCommercial-NoDerivatives 4.0 License.

https://doi.org/10.1515/9783110622096-016 


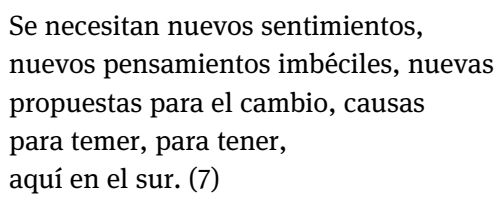

Retomo, entonces, un pasaje ya citado en el que Jorge Herralde recuerda el momento en el que conoció a Osvaldo Lamborghini y a sus compañeros de la revista Literal: "habían tomado el poder en una minúscula editorial llamada Noé, a cuyo lado la minúscula Anagrama era como Penguin. En ella publicaban una revista, en formato de libro de bolsillo alargado, llamada Literal. Me regalaron un número que encontré literalmente impenetrable”. En efecto y en contraste con una editorial de influjo transnacional como Anagrama, editoriales como Noé -este es el punto de partida-son las únicas que van a asumir los costos de la experimentación y de lo que en principio, porque no respeta la pauta de traductibilidad, puede resultar "impenetrable". También en Noé apareció El frasquito (1973), de Luis Gusmán, un texto que, no solo por su breve extensión, sino también por las mismas razones que impidieron la publicación de Tadeys, de Lamborghini, jamás podría haber sido publicado por Anagrama y, por lo tanto, haber sido incorporado a la literatura (latinoamericana) mundial. A cuarenta años de su publicación, Ezequiel Alemián, anotó que se trata "de un texto de vanguardia que quebraba la legibilidad tradicional de la literatura apelando a una sintaxis en descomposición, a un vocabulario que se nutría de términos marginales, a un referente sexualizado y opaco". La escritura experimental, por lo tanto, necesita de esos reductos desmarcados de las convenciones de la industria editorial para ser posible. $\mathrm{Y}$ es allí, en el circuito localizado, donde suele permanecer y donde, eventualmente, hay que ir a su encuentro, al menos en lo que refiere a las literaturas producidas en constelaciones culturales periféricas.

Esta última observación me permite introducir y revisar postulados de Pascale Casanova que, en principio, sostienen que la literatura mundial, la que se organiza, según su modelo, en torno al centro de referencia París, sería el territorio de la experimentación, mientras que las literaturas nacionales periféricas se expresarian mediante formas retardatarias. En sus términos, que "not only does the center supply theoretical and aesthetic models to writers on the periphery; its publishing networks and critical functions jointly strengthen the fabric of universal literature" (109). Y que:

\footnotetext{
Opposed to the centripetal forces that strengthen the autonomous and unifying pole of world literary space and provide both a common measure of literary value and a literarily absolute point of reference (the Greenwich meridian) are the centrifugal forces associated
} 
with the national poles of each national space-the inertial forces that work to divide and particularize by essentializing differences, reproducing outmoded models, and nationalizing and commercializing literary life. (109)

Al margen de que los ejemplos de los que se va a valer Casanova, la España franquista y la Yugoslavia de Tito (111), son decididamente tendenciosos, la reproducción de fórmulas y la comercialización de la vida literaria son -como he argumentado- ante todo patrones que hoy regulan la literatura mundial y que, eventualmente, sí penetran la dinámica nacional, pero que difícilmente sean constatables, como condición, en los dominios locales. Más adelante, ante cierta realidad empírica irrebatible, Casanova se va a ver impelida a abandonar $\mathrm{su}$ idealismo etnocentrista y replantear sustancialmente su postulado. Va a anotar que

American (or Americanized) large-scale literary production, having effortlessly succeeded in making articles of domestic consumption pass for "international" literature, poses a grave threat to the independence of the world of letters as a whole. What is being played out today in every part of world literary space is not a rivalry between France and the United States or Great Britain but rather a struggle between the commercial pole, which in each country seeks to impose itself as a new source of literary legitimacy through the diffusion of writing that mimics the style of the modern novel, and the autonomous pole, which finds itself under siege not only in the United States and France but throughout Europe, owing to the power of international publishing giants. The American avant-garde is no less threatened today than the European avant-garde. (169)

Mi tesis, ante los mismos factores que observa Casanova y a riesgo de ser extremista, no es que el polo autónomo, en el dominio transnacional, se encuentre "amenazado", sino más bien que ese nivel, en la coyuntura actual, solo puede ser gestionado -y dominado- por la lógica heterónoma y que, por consiguiente, si todavía hay un espacio para la experimentación y la escritura de vanguardia, habría que buscarlo, retraído y con escaso impacto en la esfera pública, en los enclaves locales, principalmente, en los más apartados de los centros mundiales de gestión cultural donde la condiciones materiales exigen un uso de la imaginación crítica para sortear constricciones económicas, técnicas y legales.

Para el caso Argentino, Hernán Vanoli anota que

la paulatina recuperación de la industria editorial y del comercio del libro en nuestro país, acaecida de 2002 en adelante, tiene a las pequeñas editoriales como uno de sus principales actores, no en términos económicos pero sí en dinamismo y renovación. Ahora bien, este dinamismo, de dimensiones económicas limitadas, poco nos dice sobre las características del activismo cultural desplegado por estos emprendimientos. Lo que nos interesa destacar en primera instancia es que, antes que su característica de "editoriales de nicho" o de su supuesta "independencia" con respecto al capital financiero transnacional, lo que nos interesa de estos emprendimientos es el uso de la creatividad como insumo para la 
generación de comunidades de lectura. Justamente, es esta vocación de erigirse en principios organizativos de ciertas redes de intercambios, cooperación, amistad, gusto personal y tradiciones de autonomía cultural presentes en los sectores más activos de las clases medias urbanas, la que nos permite agruparlas en torno a unas prácticas comunes. (172-173)

Voy a tomar, de la afirmación de Vanoli, el factor creatividad como instrumento para generar posibilidades en contextos limitantes, pero a ampliar el alcance territorial: tanto en la Argentina poscrisis como en el Chile de la transición o en una Centroamérica barrida por las guerras internas y las carencias crónicas, las literaturas locales se van a fundar en la creatividad para poder impulsar un desarrollo que la industria editorial establecida no está en condiciones de promover. En toda la región, por lo tanto, desde los años 90 en adelante, van a ser valga la paradoja- las pequeñas editoriales independientes las grandes dinamizadoras de la literatura y los campos literarios. Leer la literatura latinoamericana hoy, la que anima el debate sobre los límites y posibilidades de la literatura, consiste, en este sentido, en leer las publicaciones localizadas. Frente a ellas, la literatura de circulación internacional, sería formulaica, repetitiva y, por esto mismo, también efectiva.

Como ya anticipé, la creatividad se va expresar, por lo pronto, en dos dominios con frecuencia complementarios: por un lado y ante todo, en el plano material de cómo se resuelve la elaboración del objeto libro -lo que suele implicar la activación de redes de cooperación y afinidad-y, por el otro, en la escritura misma. La red de editoriales cartoneras que producen libros a partir de cartón reciclado, témperas y fotocopias es hoy en día un fenómeno presente en todo el subcontinente y ya suficientemente estudiado; propongo revisar, por eso, otros espacios de gestión, nodos o proyectos.

Coordinada por Matilde Oliveros y Leandro Selén, 27 pulqui es una editorial activa desde fines de 2014 en la Ciudad de Buenos Aires. Se especializa en la producción de libros objeto con una tirada, sin embargo, no despreciable de quinientos ejemplares. Cada título cuenta, así, con un diseño y armado propio que lo distingue de los demás libros de la editorial y que, como procedimiento general, contrasta con las colecciones seriadas de las editoriales industriales. "Por el momento" -sostuvo la editora en una entrevista del 2015 (Friera)- "es una editorial de poesía, pero no creo que estemos cerrados a la prosa. 27 pulqui intenta que los libros no sean materiales aislados del resto de la realidad social. Intentamos que los libros estén integrados a la sociedad”. También sobre esta premisa la editorial funda su particular modo de producción: los libros son elaborados en colaboración con la imprenta recuperada Cooperativa de Trabajo Obrera Gráfica Campichuelo (Cogal) y el Taller de Oficios de la Feria de La Salada a partir de "materiales alternativos provenientes del reciclaje" (sitio web Fundación Campichuelo). La cooperativa se fundó en 1992 como reacción al vaciamiento del 
patrimonio público impulsado por el gobierno de Carlos Saúl Menem que amenazaba con dejar sin empleo a los trabajadores de la imprenta. Desde entonces, conducida y autogestionada por los empleados devenidos cooperativistas, la empresa ha logrado modernizar su infraestructura, establecer un modelo ejemplar de administración alternativa y consolidar, mediante la Fundación Campichuelo, lazos de cooperación con diversos organismos sociales. En el sitio de la Gráfica Campichuelo hoy se lee:

Hoy día sentimos orgullo por nuestro recorrido empresarial cooperativista. Somos autónomos e independientes. Contamos con maquinaria de última generación y con un equipo integrado por más de sesenta trabajadores apasionados por la impresión gráfica y dotados de años de experiencia, formación y profesionalización. Estas facultades nos permiten ser una cooperativa gráfica competitiva en el mercado argentino, especializada en brindar productos y servicios de altísima calidad con la celeridad y eficiencia que nuestros clientes demandan.

Nuestra misión es promover una gestión económicamente viable, socialmente beneficiosa y ambientalmente responsable.

Por su parte, el Taller de Oficios de la Feria de La Salada es un espacio de capacitación para personas de bajos recursos económicos dependiente de la feria popular La Salada. Durante el proceso de formación, los talleristas adquieren competencias en el rubro textil como cortadores, costureros, confeccionistas o realizadores de moldería. Su aporte a la producción de los libros de 27 pulqui consiste en revestir los libros diagramados e impresos en la Gráfica Campichuelo. En 2015 Mario Arteca publicó Piazza Navona en la editorial. Antes de eso, participó del proceso de armado del libro junto a los talleristas. Sobre esa experiencia, señaló en una entrevista que "Tal vez haberlo visto con los creadores, con los chicos del taller, da la idea de que el libro comienza a hacer otro viaje, no el de la librería, sino un viaje más social” (“A través...”). La producción de los singulares libros de 27 pulqui supone, por lo tanto, una articulación comunitaria que se desmarca claramente del circuito comercial para proponer diálogos de colaboración creativa entre diferentes sectores sociales. Sectores que, por regla general, raramente comparten espacios y proyectos. Producen libros objeto, además, que, de otro modo, sin la colaboración con sectores por tradición ajenos al circuito de libro, no poseerían las características distintivas que presentan.

Uno de los libros publicados por 27 pulqui -en coedición con Almadegoma Ediciones- es Columna norte (2016), una suerte de estuche estampado con un paisaje con dos volúmenes en su interior correspondientes, respectivamente, a selecciones de poesía reciente -todos los incluidos por el compilador Pablo Espinoza nacieron en los años 80- de las provincias siempre postergadas de Jujuy y Salta (Fig. 7). 


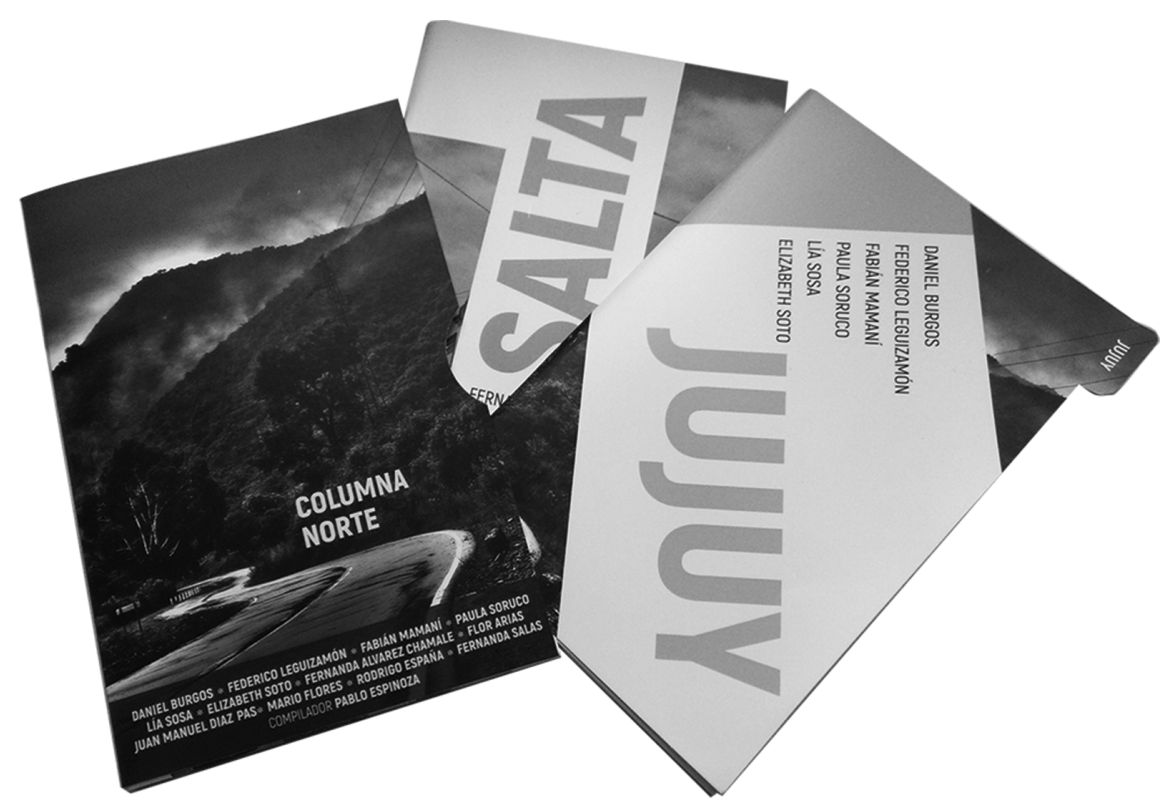

Fig. 7: El sobre y los dos volúmenes de Columna norte (2016) (@ 27 pulqui 2016. Imágenes de portada: Carolina Ventiades y Ku Mo. Diseño: Matilde Oliveros).

Con esta publicación, y la posterior Salí Dulce (2018), que reúne poetas de Tucumán y Santiago del Estero, queda plasmado el interés de la editorial por diversificar los discursos, descentrar la tradición aferrada a Buenos Aires como lugar de enunciación privilegiado dentro de la trama nacional y asignarles visibilidad a las experiencias locales periféricas y de las nuevas generaciones. Al igual que con el título Pasta base (2014), de José M. Abram Luján, que actualiza al experiencia del trabajo en la zafra en la provincia de Tucumán no solo mediante la palabra sino también por medio de un sobre de azúcar como el que alcanza al consumidor después del borrado estratégico de las marcas de producción (Fig. 8).

Dice Damián Tabarovsky que "Podría afirmarse, sin demasiado riesgo de error, que una buena parte de la narrativa argentina más interesante de la última década se publicó en pequeñas editoriales independientes" (2014). La misma proposición, no obstante, podría trasladarse "sin demasiado riesgo de error" al resto del subcontinente. Sostienen los editores de Alquimia Ediciones de Chile que, en ese país, las "condiciones de época han permitido que de un tiempo a esta parte, la mayoría de la literatura interesante que se escribe en los márgenes del Estado, pase por las editoriales independientes, e incluso muchos de los 


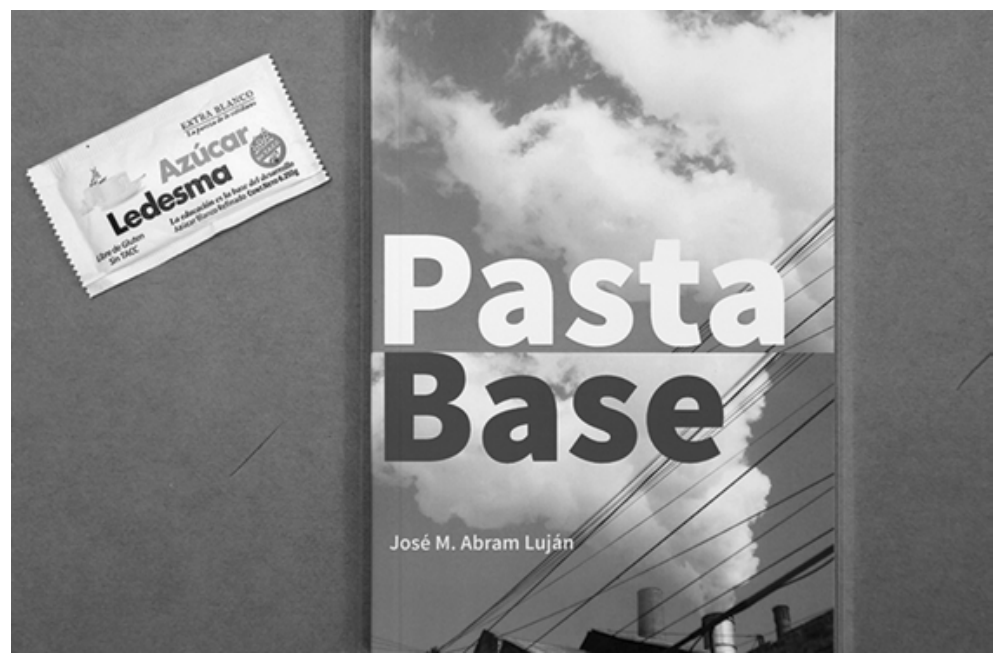

Fig. 8: Pasta base (2014), de José M. Abram Luján (৫ 27 pulqui 2014. Imagen de portada: José M. Abram Luján. Diseño: Matilde Oliveros).

autores que solía publicar en transnacionales, hoy buscan proyectos más autónomos" (“Alquimia Ediciones” 15).

Alquimia es una editorial fundada y conducida por el poeta Guido Arroyo desde 2006. De acuerdo con la información ofrecida en el sitio del "taller de trabajo y grupo de estudio" Navaja, que está a cargo de la imagen de la editorial, "Alquimia Ediciones es un proyecto que rescata una tradición de literatura social experimental latinoamericana, el objetivo de su editor es consolidar un catálogo donde se crucen dos elementos; economía en los recursos como propuesta ideológica y que sus libros y portadas sean visualmente impactantes”. Es también la editorial a la que se acercó Matías Celedón (Santiago de Chile, 1981) después de publicar Trama y urdimbre (2007) en Random House Mondadori.

Alquimia publica libros con formatos diversos, siempre cuidados, pero también una colección de bolsillo más o menos estandarizada que, si no fuera por la incorporación de fotos en interiores y los collages del diseñador de Navaja en portada, da la impresión de que podría pertenecer a cualquier editorial del circuito comercial convencional: Foja Cero. La colección, no obstante, se caracteriza por el bajo costo de venta al público, unos 10 Euros, y por el decidido riesgo formal de sus propuestas. De Esta parcela (2015), de Guadalupe Santa Cruz, por ejemplo, las reseñas consignan que "es un objeto difícil de clasificar, tanto que pareciera que 'libro', 'poesía' o 'narrativa' son etiquetas que nunca se le ajustan 
completamente" (Cárcamo) o que "Para adentrarnos en su lectura hay que aceptar que el pacto tácito que supone un relato se encuentra anulado. En lugar de toparnos con una escritura clara, al servicio de lo narrado, experimentaremos (con) una prosa abigarrada, barroca, que se revela contra ese designio, aproximándose al silencio, al estrépito de la poesía” (Foerster Montecino). Acaso gracias a esta posibilidad de acoger escrituras inclasificables, en esta colección también apareció La filial (2012), de Celedón (Fig. 9). Después de la experiencia con Random House Mondadori, donde cabría deducir que el margen para la experimentación resultaba estrecho para su proyecto, Celedón migró a Alquimia y, con esto, también invirtió el itinerario natural, el prefijado para los escritores latinoamericanos.
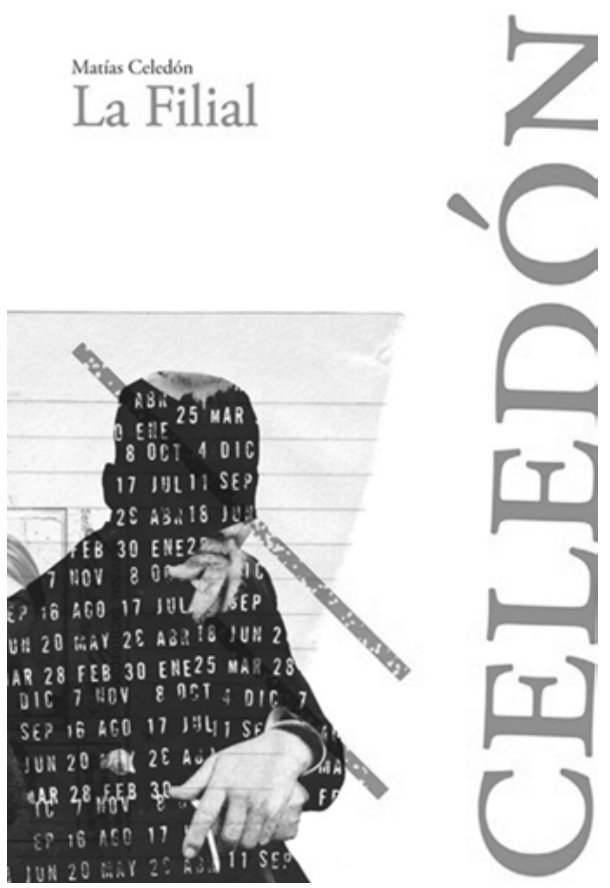

Fig. 9: Portada de La filial (2012), de Matías Celedón (@ Alquimia Ediciones 2012. Diseño de portada: Navaja).

El relato contenido en $L$ a filial es borroso, acaso trivial, sin acontecimientos: en una oficina se corta la luz, la conexión telefónica y los empleados son retenidos en el edificio y de alguna manera compelidos a seguir con su rutina de trabajo. Durante días: al principio es el 5 de junio del 2008, hacia el final, cuando se restituye en suministro eléctrico, el 18. Mientras tanto, durante esos días, no 
pareciera pasar mucho más que algunas interacciones difusas, atravesadas por el deseo y la violencia, entre personajes apenas nombrados como "la ciega", "el manco" o "la coja". El narrador, también vagamente delineado, anuncia: "interrumpo mis labores cotidianas para dejar constancia" (9), pero su relato jamás va a tomar forma orgánica ni a ofrecer descripciones del entorno que lo rodea. Al final, una "Nota de edición" ya fuera del orden diegético informa que La filial fue escrito y realizado con un sello Trodat 4253, con tipos móviles de 3mm y 4mm, en dos tablillas de seis líneas con un máximo de noventa caracteres por impresión” (203). Con esta nota termina de revelarse cuál fue el ejercicio experimental llevado a cabo por Celedón y puesto en circulación como libro por Alquimia: cada una de las páginas de $L a$ filial está compuesta y ocupada por un único timbrado donde, como máximo, se podían incluir 90 caracteres (Fig. 10).

Antes clasificable como performance, el proyecto de Matías Celedón consistió en elaborar con el sello, en un espacio cerrado y durante un horario de oficina regular, una cantidad significativa de originales y reproducir, así, la experiencia de trabajo mecánico y alienado. De esta manera, en la materialidad del texto quedaría inscripta la instancia de elaboración y, con ella, una reflexión

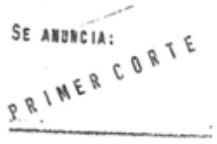

I"ITERUMPO MIS LABORES

COTIOIALAS PARA OE JAR

CONSTANICIA.

Fig. 10: Interiores de La filial (@ Alquimia Ediciones 2012. Diagramación: Cristián Jara). 
sobre el trabajo humano subordinado a demandas institucionales. Si bien el proyecto solo llego a concretarse como una reproducción digital de un único original efectivamente timbrado sobre un libro de actas, designado como "holotipo" entre cinco pruebas, el resultado no deja de ser una apuesta desafiante tanto en lo que refiere a las lecturas que habilita en relación con la cultura del trabajo en el Chile posdictatorial como en lo que respecta a la propuesta literaria en sí: una que desborda los límites trazados por las prescripciones de la industria editorial y el consenso general acerca del fenómeno literario. Se trata, por esto mismo, de un libro de circulación circunscripta y silenciosa, difícilmente digerible por la lógica de gestión de literatura mundial. ${ }^{1}$

Libros del Pez Espiral es un concepto editorial gestionado por Daniel Madrid en Santiago de Chile desde fines de 2012. Consultado sobre la noción de independencia en la que funda su proyecto, Madrid dice que

lo único que se le podría pedir a una editorial pequeña e independiente es que, a diferencia de las transnacionales o de las editoriales grandes, no se deje gobernar por criterios puramente comerciales, sino que se atreva a publicar autores y textos poco rentables en términos económicos. Ese gesto mínimo de resistencia, por pequeño que parezca, es decisivo en un mundo gobernado por la rentabilidad.

(Zanetti)

Lo que distingue a las publicaciones de Pez Espiral es el altísimo cuidado estético de los soportes, ya que, mediante un meditado trabajo con la materialidad de los libros, cada título adquiere un aspecto visual único donde queda plasmado algo de lo contenido en la trama textual. De esta manera, la política editorial de fondo, al igual que la de 27 pulqui, propone un quiebre con la producción seriada, con base en una maqueta única, de la industria convencional. Sobre este punto, Madrid precisa que "para nosotros la materialidad es una cualidad transgresora en un medio donde la mayoría de los libros no salen de líneas de producción masivas, pues la mayoría de las editoriales tienden a caer en la estética de las colecciones, olvidando u obviando que cada libro es una unidad y, por ende, requiere de una forma particular" (Zanetti). Conscientemente, la editorial procura retomar e inscribirse en la mejor tradición local de libro de autor y que sus propios libros, aunque reproducidos mediante técnicas de impresión estándares, no renuncien a la personalidad y valgan por sí mismos como objetos estéticos y semióticos. En la autopresentación que la editorial ofrece en su sitio web se lee:

1 Hasta el momento, solo se cuenta una traducción de La filial. Bajo el título The Subsidiary (2016), la traducción al inglés apareció en la editorial independiente con sede en Brooklyn Melville House. 
Nos proponemos celebrar la poética de cada uno de los libros que publicamos. Para ello creamos ideas basadas en una lectura gráfica, objetual y material que potencie las cualidades propias de las obras. Seguimos la senda de editores como Guillermo Deisler en Ediciones Mimbre y UNI/vers(;); Juan Luis Martínez en Ediciones Archivo; Enrique Gómez-Correa y Braulio Arenas en Ediciones Mandrágora; Ludwig Zeller y Susana Wald en Oasis Publications, por nombrar algunos referentes cercanos.

Estas pautas procedimentales, se podría suponer, convierten a los libros de Pez Espiral en un bien restrictivo, elitista, sin embargo, su precio de venta al pública, que ronda los 10 Euros, se ubica en el rango de los libros de bolsillo convencionales. Esto, a su vez, va acompañado de una licencia flexible, de libre reproducción, siempre que no conlleve algún tipo de usufructo económico. En concreto, en la página legal de los libros aparece consignado que "Está permitida la reproducción, difusión, exposición al público y representación, siempre que no sea con fines comerciales o de lucro y a condición que sean citados el autor, la editorial y el contexto de origen”. De este modo, Pez Espiral se permite el raro lujo de poner en circulación 500 ejemplares de libros tratados muy cuidadosamente, con un costo de producción sin duda considerable, y, sin embargo, accesibles y orientados a una difusión desmarcada de la de carácter netamente comercial.

Este manifiesto interés de Pez Espiral por la dimensión material del libro no agota, sin embargo, el aporte de la editorial a la cultura literaria, pues contenidos en esos singulares artefactos se pueden encontrar textos fuertemente disruptivos, compuestos, en la mayoría de los casos, por escritores emergentes desconocidos dentro del circuito editorial convencional. Uno de ellos es Francisco Ovando (Rancagua, 1989).

Su libro Acerca de Suárez (2016) es una prueba contundente de la excelencia con que Pez Espiral articula el cuidado de los soportes con propuestas textuales siempre iconoclastas y perturbadoras. El artefacto, compuesto en un formato grande de $24 \times 16 \mathrm{~cm}$, está revestido en sus tapas de un color dorado brillante que, con una natural pérdida de brillo, se mantiene en interiores, incluso en la tipografía (Fig. 13).

Este revestimiento, que le otorga al libro la apariencia de un objeto metálico, reforzada, a su vez, porque la portada aparece libre de títulos o imágenes (Fig. 11), ubica el objeto en un orden semántico que remite tanto a la luz -uno de los tópicos que organizan la narración- como el cobre, en tanto mineral de primera importancia para la economía - material y simbólica - chilena. Este mineral, además, va a aparecer invocado en la trama textual en la forma de "un plato colorado, metálico. [...] un corte transversal de uno de los grandes cables de cobre que viene del embalse" (13), un curioso objeto que trae Jonás, el extranjero, al pueblo donde transcurren los hechos. 


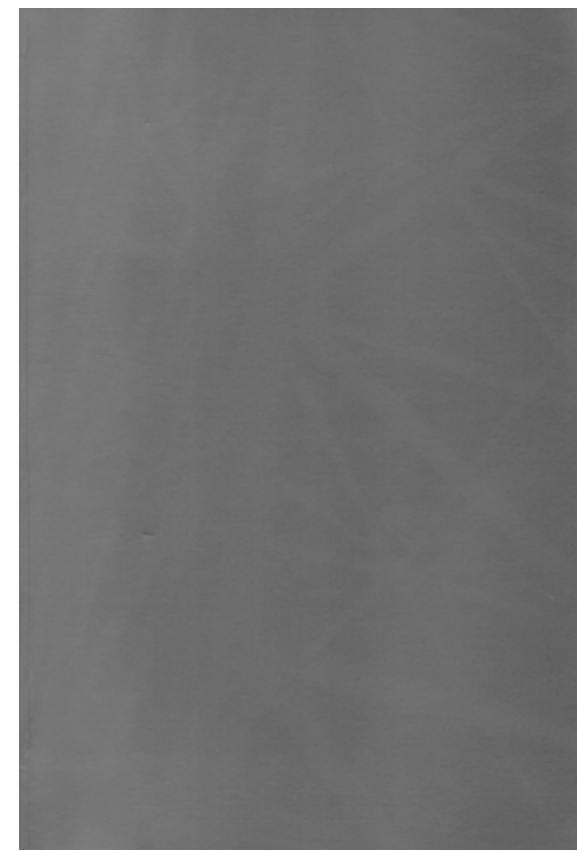

Fig. 11: Portada de Acerca de Suárez (2016), de Francisco Ovando (C) Libros del Pez Espiral 2016).

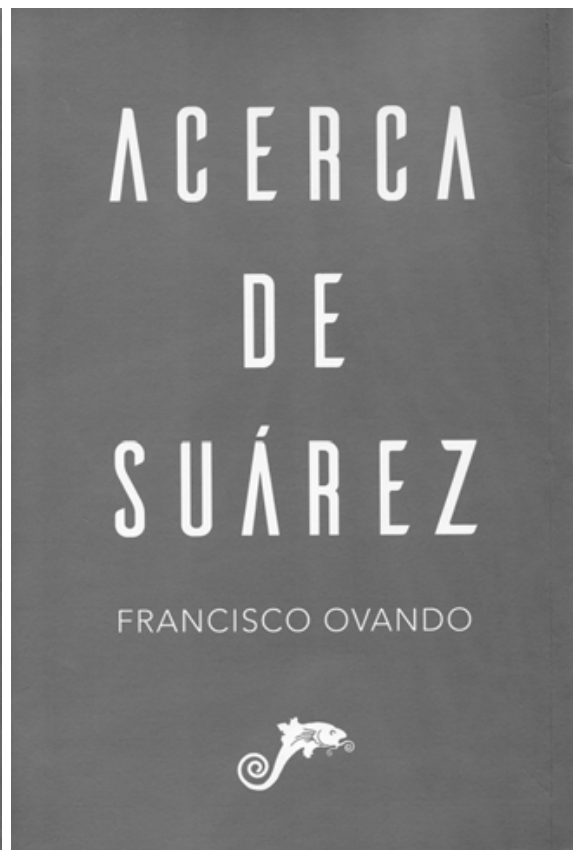

Fig. 12: Contraportada de Acerca de Suárez (2016), de Francisco Ovando (C) Libros del Pez Espiral 2016).

Donde por convención y hábito debería encontrarse la portada, unos trazos que podrían valer por destellos- apenas distinguibles, en negativo, van a revelar en el lado interior de la portada y, más adelante durante la lectura, la silueta de torres de alta tensión. La solapa de la portada, también libre de inscripciones, no interrumpe, al desplegarla, el dorado continuo de la tapa. El título del libro va a aparecer, por su parte, impreso en blanco en la contraportada, acompañado por el nombre de Ovando como sujeto autor y más abajo el logo de la editorial (Fig. 12). Al abrir el libro, sobre la guarda también de color dorado, a modo de portadilla, se lee "La electricidad es la revolución”. Así, el soporte, organizado de este modo, ya crea un efecto de positivo extrañamiento que anticipa y emula el que va a producir la lectura.

El relato, que se resuelve en escasas 59 páginas y tres capítulos, va a ser conducido al menos por dos voces narrativas: una en primera, homodiegética, que va a oscilar entre el yo y el nosotros, y una en tercera, heterodiegética y omnisciente. El argumento transcurre en un pequeño pueblo acosado por la sequía, rodeado de enormes dunas de arena y aislado del mundo exterior. La 
electricidad al igual que noticias o visitantes de más allá llegan interrumpidamente y concentran tanto las esperanzas como los miedos de los habitantes del pueblo. La peste, aunque incierta, atemorizante, en cambio, va a llegar un día para quedarse. En este contexto, opresivo y onírico, Suárez, el responsable de la limpieza del consultorio del pueblo, se va a convertir en un médico improvisado pero poderoso que va a acabar con la vida de Jonás hijo, quien estaba destinado a relevar a su padre como encargado de mantener en funcionamiento las torres de alta tensión en los extramuros. Antes, para que Suárez intente la cura, Jonás le ofrece una herramienta que, en tal contexto, adquiere un valor de uso extraordinario: un generador eléctrico. "Mire, Suárez, le dice [Jonás padre], si me lo sana al niño yo le dejo el generador, y con el generador usted dirá cuándo hay y cuándo no electricidad, y entonces... Pero no es necesario que siga. Suárez ya imagina. Se ve a sí mismo recubierto de una importancia que ya no dependerá del azar, del ir y venir de la corriente alterna” (31). Jiménez, el encargado de vigilar el horizonte y anunciar la eventual llegada de visitantes, por su parte, va a ser testigo casual de la muerte y, con eso, en tanto poseedora de un secreto comprometedor, convertirse en una figura de contrapeso. Finalmente, va a persuadir a Suárez para que se aventure en el desierto en busca de alguna cura para la peste y, así, logra que el pueblo retorne a la rutina, "a un cauce familiar. A algo", -dice el narrador, Jiménez-, "que conocíamos" (59) y que lo restituye a él mismo como una figura de poder apreciable.

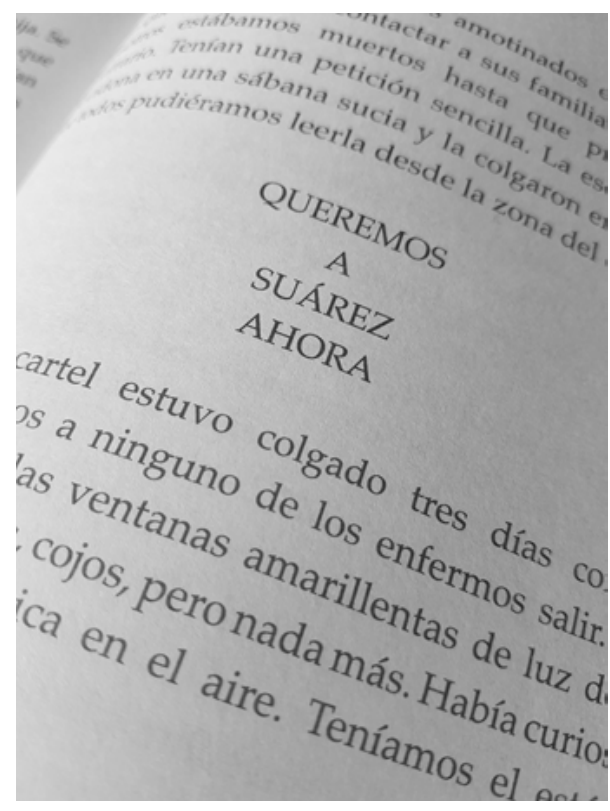

Fig. 13: Interiores de Acerca de Suárez (৫) Libros del Pez Espiral 2016). 
De este modo, Ovando articula un sutil relato donde la escasez de recursos -otra vez, como en La filial, la falta de energía eléctrica- y el poder son los ejes conductores, pero, antes que ofrecer un retrato verosímil y realista, opta por construir una lograda alegoría tejida, a conciencia de las implicancias, con palabras. Nos ubica, sí, en un lugar donde la modernidad ideal ha fracasado, donde los artefactos eléctricos han devenido obsoletos no por superación sino por carencia y donde el cobre es un bien tan fetichizado como inútil. Un lugar donde, como señala Lorena Amaro, "se hace reconocible una crisis política y social que podría ser la de Chile... o la del mundo entero". Sí. Pero sería injusto decir que el relato de Ovando es, simplemente, una denuncia o un reclamo en clave, pues también puede ser leído como un elaborado poema que, puesto que sospecha de la facultad mimética de la palabra, opta por explorar los pliegues y versatilidades del significante: "Moverse por el desierto es entonar un mantra. Después de cada duna hay una duna y una duna. No mires atrás. Olvida que caminas” (26).

Por estas razones, porque el lenguaje de Ovando no es servil y, por lo tanto, no se subordina a la narración útil, porque es en este nivel -en el de la palabra y sus imágenes- donde está su mayor acierto, porque la dispersión de voces narrativas no respeta el protocolo convencional y también porque esto último se agrava con que solo escribió 59 páginas y, finalmente, con 59 páginas, según ciertos estándares de la industria editorial, no llega a componer una "novela"; por esto, Acerca de Suárez es un texto que reclama que los lectores internacionales vayan a su encuentro o, de otro modo, acepten prescindir de él.

No puedo cerrar este selectivo panorama de la publicación experimental sin hacer mención al proyecto Casa Bizarra y sus posteriores derivas. Los años noventa en Guatemala representan el inicio de una transición conflictiva hacia la pacificación del país bajo condiciones de severa desigualdad social. En 1996 un grupo de jóvenes artistas, escritores y activistas se congrega en un lugar físico de la Zona 1 de la capital para fundar e impulsar el proyecto colectivo, café literario, galería, sala de conciertos, bar y lugar de encuentro Casa Bizarra, que, rápidamente y a pesar de que el lugar concreto dejó de existir dos años después, se convertiría en el centro gravitacional de la contracultura del país. Entre los gestores principales y del entorno inmediato se contaban Simón Pedroza, Giovanni Pinzón, Josué Eleazar, Emily Hazle, Pablo Robledo, Francisco Toralla, José Osorio, Daniela e Itziar Sagone, Yasmín Hage y Pablo Bromo. No es este el espacio para reconstruir la historia de este lugar de gestión del que, evaluado en perspectiva, se puede sostener que, efectivamente, llegó a rediseñar el mapa de la cultura artística local y regional, ${ }^{2}$ pero creo que corresponde que incluya al

2 Para más información, se puede consultar Hass (99 y ss.) y Shillington (161 y ss.). 
menos la referencia a dos proyectos editoriales que se gestaron dentro de la trama social desplegada desde esa usina cultural y bajo su espíritu. Se trata de Editorial X, de Estuardo Prado, y, Ediciones Mundo Bizarro, de Simón Pedroza, las dos fundadas en 1998.

Derivada del fanzine Anomia, Editorial X existió como tal hasta el 2003 con el firme propósito -declarado en un mítico manifiesto- de convulsionar la escena literaria establecida y otorgarle visibilidad a las nuevas generaciones de escritores. En ese período, Estuardo Prado publicó, en un formato mínimo y simple, $15 \times 10 \mathrm{~cm}$, sin nombre de autor en la tapa, una serie de títulos, hoy legendarios, de escritores como Javier Payeras, Maurice Echeverría, Ronald Flores, Byron Quiñónez, Jacinta Escudos, Francisco Méndez y del mismo editor, entre otros, el libro de relatos Los amos de la noche (2001) del que Alan Mills ha escrito que "podía leerse como una tentativa de terrorismo moral, un verdadero atentado léxico, el cual incluso buscaba situarse por afuera del mero hecho literario". Después de un período de silencio de diez años, el editor y escritor volvió a aparecer en el 2013 con un relanzamiento de la editorial bajo el nombre e/X, donde, en conformidad con su espíritu original, han aparecido títulos de escritores emergentes como Pep Balcárcel (Guatemala, 1993). Para ese mismo entonces, algunas reediciones de los “clásicos” de Editorial X, a su vez, fueron asumidas por la editorial Germinal de Costa Rica. En 2017 e/X dio a conocer un libro de relatos titulado Pulp, también de Estuardo, con un precio de venta al público que ronda los 4 Euros. Se trata en muchos sentidos de un libro anómalo: con un collage de Alejandro Marré en portada y contraportada, en tamaño media carta, sin títulos en el lomo y con una estética general, incluidas ilustraciones en interiores, que aleja el objeto de la tradición visual del libro literario para ubicarlo en la corriente pulp de cómics baratos para consumo popular que tuvo su apogeo en Estados Unidos durante los años 20 y 30 del siglo pasado (Fig. 14).

Por esto, en una reseña redactada por Jaime Moreno para El Periódico se lee que "Lo primero que llama la atención en la nueva apuesta de Prado es su composición”. Y a continuación que

Parece una colección de cuentos, pero no lo es; se asemeja a un cómic en tamaño, forma y material, pero tampoco. Es, en todo sentido, un producto experimental. "La idea siempre ha sido hacer libros que no son libros”, explica Prado, quien ya había incursionado en este juego con Amos de la noche. "He tratado de hacer textos híbridos en los que las fronteras entre un género y otro sean porosas”, puntualiza. El autor explica la propuesta como un juego de imágenes, tanto en el lenguaje como en la conformación misma del libro.

Simón Pedroza, por su parte, ha sostenido su proyecto editorial hasta el presente, pero en constante mutación. De la temprana Ediciones Mundo Bizarro, su emprendimiento evolucionó hacia Folio 114 - del que aseguró que "Es un colectivo de 


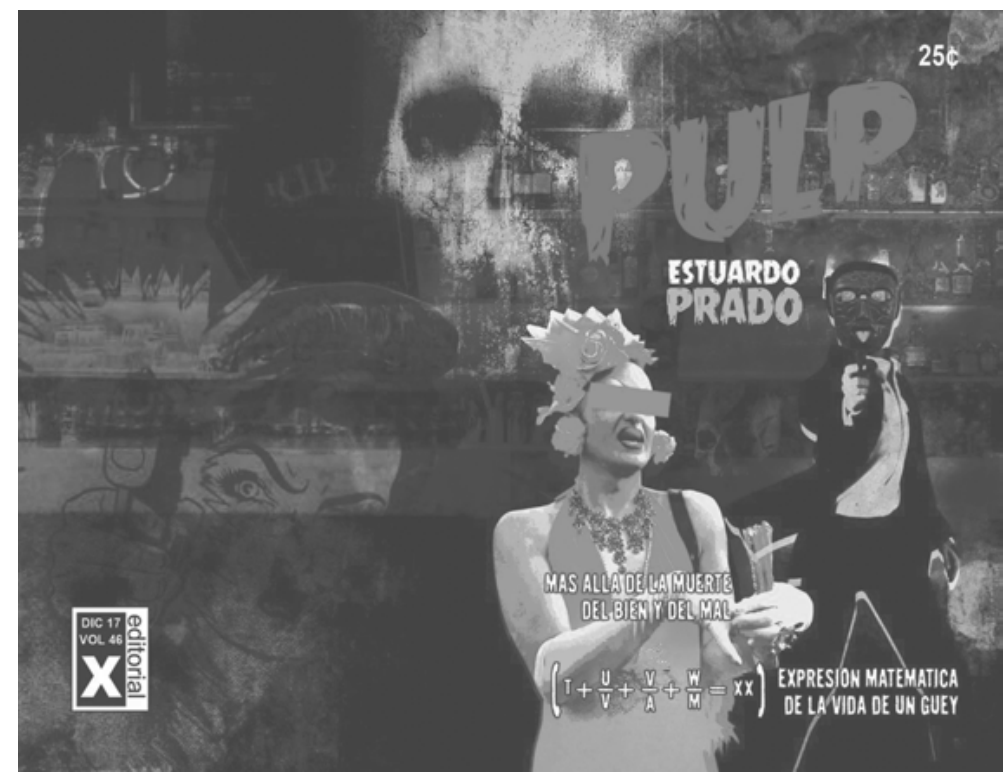

Fig. 14: Portada y contraportada de Pulp (2017), de Estuardo Prado (@ Editorial X 2017. Imagen de portada: Alejandro Marré).

poetas y artistas interesados en la promoción honesta y desinteresada del arte y la literatura con fines netamente culturales y sociales, a nivel nacional y con proyección regional"- para desembocar en Ediciones Bizarras. En todos los casos se trata, sin embargo, de la producción de objetos -por momentos ya no exactamente de libros-, compuestos a mano por el editor y poeta, que desde la materialidad intentan -y logran- ser singulares y expresivos. Sin ISBN ni registro de licencia alguna, los objetos se consiguen en ferias alternativas, fiestas y por pedido vía internet, donde también se pueden encontrar títulos liberados como pdf. Con talleres de encuadernación y armado de libros en espacios por regla general ajenos a la literatura, como la Granja Modelo de Rehabilitación Pavón, la gestación de enlaces sociales creativos también constituye un principio articulador en el que se funda la labor de Pedroza. A su trabajo manual se deben libros en casos simples, en casos de compleja elaboración, siempre cuidados, de, por ejemplo, Javier Payeras, Pablo Bromo y José Eluazar y más tarde, ya con Folio 114 y Ediciones Bizarras, de Diana Ortiz, Manuel Tzoc, Manuel Enrique Rodríguez, Alex Rodríguez, Pedro Chavajay y, entre otros, entre quienes cuenta el mismo Pedroza, Nicole Delgado.

Uno de los libros publicados por Pedroza es Terrorismo moral y ético (1999) que reúne poemas de Payeras, Marré y Pedroza en cien páginas de papel reciclado ilustradas en un tamaño de $11 \times 8.5 \mathrm{~cm}$ (Fig. 15). 


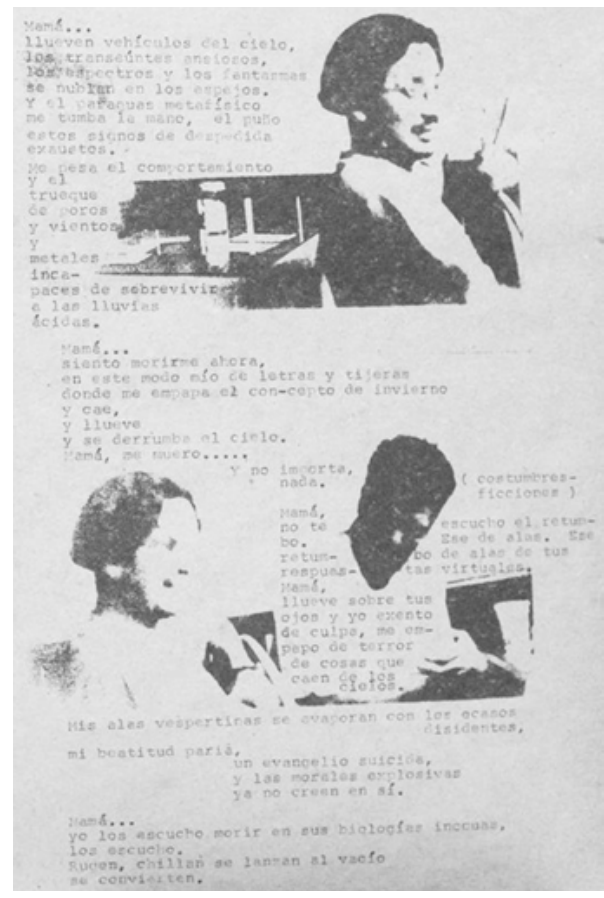

Fig. 15: Interiores de Terrorismo moral y ético (1999) (@ Ediciones Mundo Bizarro 1999).

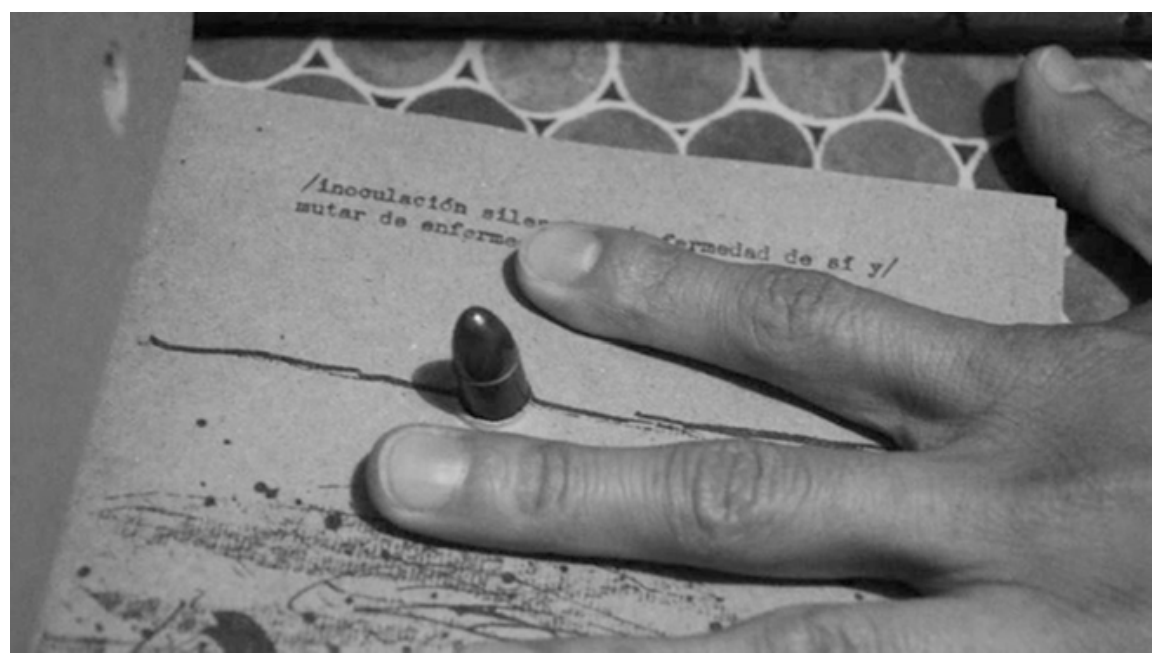

Fig. 16: Interiores de Automátika 9mm (2001 y 2016) (@ Ediciones Mundo Bizarro 2001. Imagen: (C) GT Cultura 2018). 
También del mismo trío es el mítico libro objeto Automátika 9mm (2001 y 2016) cuyo rasgo distintivo consiste en estar atravesado por una bala (Fig. 16) que remite tanto a un entorno social castigado por la guerra fratricida y el derrame cotidiano de sangre como, hacia dentro, a una poesía signada por la violencia.

De Manuel Tzoc (Guatemala 1982), un poeta y permorfer que procura construir una identidad al mismo tiempo homosexual e indígena, es escop(o) etas para una muerte en versos b... a la (2006 y 2015). También él ha devenido, junto con Rodrigo Arenas, editor. Juntos coordinan la editorial artesanal especializada en literatura queer La maleta ilegal. Concluyo de este dato que la experiencia de fines de los 90 en la ciudad de Guatemala ha dejado un fuerte legado, inspirado en Casa Bizarra, que promueve la autogestión, el activismo de enlace político-cultural, el tejido de redes de sociabilización alternativas y, finalmente, la edición artesanal. Alejandro Marré está a cargo de la estética y el diseño de portadas de Catafixia, una editorial sin fines de lucro, que libera pdfs en internet, conducida, desde 2010, por los también poetas Luis Méndez Salinas y Carmen Lucía Alvarado. Pablo Bromo, por su parte, es el editor de la revista y editorial Vueltegato. Chuleta de Cerdo, también asistida en la gráfica por Marré, es otra editorial, con sede en Quetzaltenango, conducida desde 2009 por Alberto Arzú, quien, por ejemplo, publicó en e/X, 10/14 (2015). Todos, las nuevas generaciones de escritores, artistas y editores alternativos con los que hicieron escuela en el entorno de Casa Bizarra y la Editorial X junto con pares de países cercanos como Nicaragua y Costa Rica, confluyen, regularmente, en La valiente, una feria del libro, como varias otras a lo largo de toda América Latina -la FLIA o la Furia del Libro-, autogestionada. Un particular laboratorio de sociabilidad en torno a la edición independiente, las literaturas locales y la experimentación formal en un país donde todavía predomina el analfabetismo, la violencia y la inoperancia estatal. También un país donde, para el mundo -incluso, para esa franja que vale por "especializada"-, solo pareciera haber dos escritores: Eduardo Halfon y Rodrigo Rey Rosa, los únicos dos que en tiempos recientes, después de Miguel Ángel Asturias y Rigoberta Menchú, han logrado (in)filtrarse en la literatura mundial.

Creo que con este breve y parcial mapeado basta para sostener que los pequeños proyectos editoriales conforman hoy en día, frente a la industria editorial concentrada, la plataforma de gestión y producción más sugerente para y de la literatura latinoamericana. Es a esta escala microlocalizada, intrascendente en términos de rentabilidad económica y de cobertura geográfica, pero insoslayable desde el punto de vista de la renovación estética que impulsan, donde un tipo de literatura latinoamericana, definida por las condiciones de producción particulares que la sustentan y orientada fundamentalmente a la experimentación, cobra forma. La elaboración de libros más o menos artesanales, a baja escala y sin 
mayores posibilidades de circulación así como las condiciones contextuales de precariedad relativa se convierten, así, mediante la explotación intensiva de la imaginación crítica, en factores que favorecen una experimentación con formas y formatos, y una autonomía difícilmente hallables en el circuito de mayor impacto internacional. Por eso, frente a los postulados de su discípula Pascale Casanova, resulta perfectamente actualizable para el contexto que acá interesa la observación de Bourdieu que proclama que

Es claro que el bastión central de la resistencia a las fuerzas del mercado está constituido, hoy, por esos pequeños editores, que, enraizados en una tradición nacional de vanguardismo inseparablemente literario y político (manifiesto también en el dominio del cine), se constituyen en los defensores de los autores y de las literaturas de investigación de todos los países política y/o literariamente dominados.

(“Una revolución...” 263)

En tanto nodos de gestión alternativa, disidente, que se aparta de las pautas y convenciones de la industria cultural hegemónica, y al activar, así, enlaces de diálogo y cooperación entre sujetos y colectivos, las editoriales latinoamericanas independientes son siempre y al mismo tiempo -con lo que estaría enunciando una de sus condiciones- proyectos culturales y políticos. En casos, la producción y puesta en circulación corre por cuenta de un único sujeto, en casos, por el contrario, está a cargo de un colectivo, siempre, sin embargo, las rivalidades y la competencia que gobiernan la lógica de gestión hegemónica van a diluirse para dar paso a circuitos translocales de solidaridad y complementariedad, de transferencia de saberes e intercambio de experiencias e imaginación crítica. Un tipo de dinámica, también, que no puede ser disociada de sus anclajes territoriales. Dice Bourdieu que "defender la tradición francesa no es, en este caso, ceder al nacionalismo, sino defender las conquistas, intrínsecamente internacionales e internacionalistas, de toda la historia acumulativa de la literatura" ("Una revolución..." 263). Defender la producción local latinoamericana -en vista del escenario expuesto- no sería, tampoco, otra cosa que defender la literatura a secas. 